\title{
Prisão cautelar, argumentação e proporcionalidade: uma proposta para a fundamentação das decisões judiciais
}

\author{
Pretrial detention, reasoning and proportionality: \\ a proposal for the justification of judicial decisions
}

\section{Matheus Arcangelo Fedato ${ }^{1}$}

Universidade Estadual do Norte do Paraná - Jacarezinho, Paraná, Brasil matheus.fedato@outlook.com http://lattes.cnpq.br/3563256627563717

D http://orcid.org/0000-0003-1243-5127

\section{Luiz Fernando Kazmierczak ${ }^{2}$}

Universidade Estadual do Norte do Paraná - Jacarezinho, Paraná, Brasil

lfkaz@uenp.edu.br

http://lattes.cnpq.br/7437009978505769

http://orcid.org/0000-0003-0653-6255

\begin{abstract}
Resumo: A pesquisa busca solucionar o problema da falta de um modelo adequado para a fundamentação das decisões que tratam sobre prisões cautelares tendo em vista a sua inadequada aplicação prática. Utiliza-se como hipótese um modelo argumentativo baseado na proporcionalidade e apresentado em forma de axiomas, o qual seria capaz de resolver o problema da fundamentação, pois atrelado a preservação de direitos
\end{abstract}

1 Mestre em Ciência Jurídica pela Universidade Estadual do Norte do Paraná (UENP). Bacharel em Direito pela Universidade Estadual do Norte do Paraná (UENP).

2 Doutor em Direito Penal pela Pontifícia Universidade Católica de São Paulo (PUC/SP), Mestre em Ciência Jurídica pela Universidade Estadual do Norte do Paraná (UENP) e Graduado em Direito pela Universidade Estadual do Norte do Paraná (UENP) na Faculdade Estadual de Direito do Norte Pioneiro. Professor Adjunto na Universidade Estadual do Norte do Paraná (UENP), na graduação e no Programa de Pós-graduação em Ciência Jurídica (Mestrado). 
fundamentais. Objetiva-se, então, estabelecer um modelo para a fundamentação de decisões judiciais que tratam sobre prisões cautelares com vistas a reduzir a discricionariedade. Para atingir o objetivo do estudo, foi empregado o método dedutivo, além dos meios de pesquisa eletrônico e bibliográfico. As pesquisas se deram por meio de doutrinas gerais e específicas sobre o assunto, bem como artigos científicos. Como referencial teórico utiliza-se a doutrina de Robert Alexy, de Luigi Ferrajoli, bem como a crítica hermenêutica do direito de Lenio Streck. Conclui-se pela necessária utilização da proporcionalidade a partir de uma leitura da hermenêutica filosófica pela decisão que decreta ou mantém prisões cautelares, sendo sempre necessário atentar-se para a gravidade da medida imposta e o fim que ela procura tutelar. Não se deve admitir medidas inadequadas, desnecessárias ou extremamente gravosas, devendo-se observar as circunstâncias concretas do fato, sendo incabíveis motivações genéricas e abstratas.

Palavras-chave: Prisão Cautelar; Proporcionalidade; Fundamentação; Argumentação Jurídica; Discricionariedade.

ABSTRACT: The research seeks to solve the problem of the lack of an adequate model to base the decisions that deal with pretrial detentions in view of its inadequate practical application. It is used as hypothesis an argumentative model based on proportionality and presented in the form of axioms, which would be able to solve the problem of reasoning, because linked to the preservation of fundamental rights. The objective is, then, to establish a model for the foundation of court decisions dealing with precautionary arrests with a view to reducing discretion. To achieve the objective of the study, the deductive method was employed, in addition to the electronic and bibliographic research means. The research took place through general and specific doctrines on the subject, as well as scientific articles. The theoretical framework uses the doctrine of Robert Alexy, of Luigi Ferrajoli, as well as the hermeneutic critique of Lenio Streck's. It is concluded by the necessary use of proportionality from a reading of philosophical hermeneutics by the decision that decrees or maintains pretrial detentions, being always necessary to pay attention to the gravity of the imposed measure and the end that it seeks to protect. Inadequate, unnecessary or extremely serious measures must not be admitted, and the concrete circumstances of the fact must be observed, being the generic and abstract motives inadmissible.

KEYwORDs: Pretrial detention; Proportionality; Reasoning; Legal Reasoning; Discretion. 
SuMÁRIO: Introdução; 1. Considerações sobre a proporcionalidade e a argumentação jurídica; 2 . Como construir argumentativamente uma decisão que decreta ou mantém prisões cautelares no processo penal?; Considerações Finais; Referências.

\section{INTRODUÇÃO}

Inicia-se o trabalho buscando responder a seguinte pergunta "Como construir argumentativamente uma decisão que decreta ou mantém prisões cautelares no Processo Penal?”. Busca-se na proporcionalidade um modo de conseguir aplicar o Direito de forma a preservar os direitos fundamentais, no sentido de um garantismo penal. O dever de fundamentação das decisões judiciais encontra-se previsto constitucionalmente, sendo tratado pelo artigo 93, IX, que diz que todos os julgamentos dos órgãos do Poder Judiciário serão públicos, e fundamentadas todas as decisões, sob pena de nulidade.

Ainda, nesse sentido, estão o artigo 564, V, do Código de Processo Penal (CPP), que trata das nulidades e que prevê sua ocorrência quando houver decisão carente de fundamentação, o artigo 283 do CPP, dizendo que ninguém poderá ser preso senão em flagrante delito ou por ordem escrita e fundamentada da autoridade judiciária competente, em decorrência de prisão cautelar ou em virtude de sentença condenatória transitada em julgado, e o artigo 315, também do CPP, que determina que a decisão que decretar, substituir ou denegar a prisão preventiva será sempre motivada e fundamentada.

O objeto do trabalho é a decisão judicial que trata sobre prisões cautelares, mantendo-as ou decretando-as. A pesquisa situa-se na fundamentação dessas decisões, especificamente na aplicação da proporcionalidade e da argumentação utilizada para fundamentá-la. Para além da teoria crítica das prisões cautelares, é preciso analisar onde e como a proporcionalidade se encaixa e se relaciona com as prisões cautelares, principalmente como superação do binômio prisão-liberdade, fornecendo alternativas menos danosas do que a prisão. 
Busca-se, então, propor um modelo argumentativo para a fundamentação das decisões judiciais que tratam sobre prisões cautelares baseado na proporcionalidade, o qual se encontra disposto em forma de axiomas na segunda parte do artigo.

Como referencial teórico utiliza-se a crítica hermenêutica do direito e a hermenêutica filosófica, sendo também relevantes para a pesquisa a doutrina de Robert Alexy e Luigi Ferrajoli. Para atingir o objetivo do estudo, foi empregado o método dedutivo, além dos meios de pesquisa eletrônico e bibliográfico. A aplicação do método dedutivo consiste na análise do que é considerado adequado à fundamentação das decisões para o ordenamento jurídico e para as teorias utilizadas como referenciais, procurando-se extrair, a partir dessa observação, aquilo que deve ser considerado argumentativamente indevido, levando às conclusões do artigo. As pesquisas se deram por meio de doutrinas gerais e específicas sobre o assunto, bem como artigos científicos. Com a finalidade de melhor compreensão dos tópicos do texto, serão utilizadas notas de rodapé explicativas.

\section{Considerações Sobre A PROPORCIONALIDADE E A ARGUMENTAÇÃO JURÍDICA}

As prisões cautelares ${ }^{3}$, conhecidas também como prisões processuais, ocorrem antes de uma sentença penal transitar em julgado. São acessórias (acessoriedade) ao Processo Penal e seu provimento deve guiarse pela satisfação da tutela jurisdicional. Por possuir essa característica, acaba contrariando a presunção de inocência, pois causa uma restrição à liberdade antes de eventual condenação. Isso leva a uma contraposição entre os objetivos das prisões cautelares (de modo geral, resguardar a segurança pública, e, de modo específico, assegurar a instrução criminal ou a aplicação da lei penal) e o direito à liberdade ${ }^{4}$.

3 Dividem-se as prisões cautelares em prisões preventivas e prisões temporárias. Entende-se ser a prisão em flagrante uma medida pré-cautelar, motivo pelo qual não será objeto desse estudo, conforme LOPES JUNIOR, Aury. Direito Processual Penal. 12. ed. São Paulo: Saraiva, 2015. p. 607.

4 Na lição de Odone Sanguiné: “O instituto da prisão provisória revela a irredutível antinomia de duas ordens de legitimidade, dialeticamente em oposição e que historicamente oscilam de um polo a outro na busca de um difícil 
Nessa linha, como toda prisão cautelar viola a presunção de inocência e cerceia, de alguma forma, a liberdade do indivíduo, a decisão que a decreta ou mantém exige fundamentação. Para sua utilização são necessárias várias condições, que podem ser elencadas em pressupostos (fumus commissi delicti/ periculum in libertatis) e requisitos (Arts. $312 \mathrm{e}$ 313 do CPP para prisão preventiva / Art. $1^{\circ}$, incisos I, II e III da Lei $\mathrm{n}^{\circ}$ 7.960/89 para prisão temporária). Ainda, vários princípios cercam as prisões cautelares, devendo ser observados sempre que delas se estiver tratando, sendo eles: presunção de inocência, motivação das decisões judiciais, contraditório, provisionalidade, provisoriedade, excepcionalidade e proporcionalidade.

Importante atentar-se para a característica de cautelaridade das prisões cautelares. Tais prisões devem existir para tutelar o processo penal e não tem característica de pena. Assim, uma vez resguardado o processo, ou seja, não sendo influenciado pelo acusado, as prisões cautelares não se mostram necessárias (salvo se em caso de fuga). Ainda que sejam aplicáveis, é preciso olhar, ainda, para as medidas cautelares alternativas à prisão, as quais asseguram o objeto das prisões provisórias e os direitos do acusado, que sofre um cerceamento menor de sua liberdade.

Deve-se entender que a prisão só deverá subsistir enquanto se manter a situação fática que a ensejou, não devendo permanecer após o desaparecimento de seu substrato decretador. $\mathrm{O}$ importante aqui é acautelar o processo. Veda-se a manutenção da prisão sem causa. Sua existência está atrelada a uma condição provisória, que é a existência de motivos legais que a ensejem. Ainda, a duração da medida, que deve ser sempre temporária, provisória, não devem durar mais do que o imprescindível para a instrução processual. A prisão preventiva deve ser decretada em caráter excepcional, apenas quando as outras medidas cautelares não se mostrarem suficientes, não podendo ser banalizadas. Nos dizeres de Fauzi Hassan Choukr, no processo penal constitucional “a prisão tem de ser

compromisso que satisfaça, ao mesmo tempo, as exigências as exigências da justiça individual e os imperativos da proteção social: o direito à liberdade e a presunção de inocência, de caráter individual, e o direito da sociedade de manter a ordem e a segurança para uma convivência pacífica”. SANGUINÉ, Odone. Prisão Cautelar, medidas alternativas e direitos fundamentais. Rio de Janeiro: Forense, 2014. p. 16. 
encarada como uma exceção e a liberdade como uma regra e, por isso, as privações de liberdade anteriores à sentença condenatória [...], devem ter sempre e necessariamente, fundamentação e finalidades cautelares" ${ }^{5}$.

O princípio da proporcionalidade é um dos principais princípios dentro das prisões cautelares. Visando a busca da adequação e da necessidade das medidas adotadas, o princípio da proporcionalidade deve levar em conta as características pessoais dos indivíduos e o crime cometido no caso concreto. Busca um modo de realizar os interesses pretendidos da maneira menos gravosa, ou seja, a medida que menos prejudique $o$ acusado, mas que cumpra a finalidade cautelar deve ser a utilizada.

Dentro da decisão jurídica, a verdade estará sempre submetida à valoração e, na argumentação, esses valores são utilizados como critério para demarcação de seu objeto. Assim, por exemplo, o critério da segurança pública avaliará o objeto garantia da ordem pública, ou pode-se utilizar de um critério justificador, como a credibilidade das instituições para fundamentar a garantia da ordem pública ${ }^{6}$. Trabalhar com conceitos abertos e valorativos é muito complicado e pode macular a fundamentação de uma decisão. Nesse sentido, como sistema de controle da decisão, as teorias da argumentação jurídica são de extrema importância, conferindo racionalidade à decisão judicial.

Para tanto, introduz-se a temática das teorias da argumentação jurídica. A argumentação (argumentatio) era designada como probatio por Quintiliano e como confirmatio por Cícero, e estava inserida, desde a Antiguidade, como uma das partes da retórica, sendo dela uma componente das mais importantes, pois visava à credibilidade dos discursos ${ }^{7}$. Ambos os autores tiveram a influência de Aristóteles, um dos primeiros a inserir a argumentação no contexto da Retórica. Com a obra de mesmo nome, o filósofo grego a define como a faculdade de descobrir especulativamente sobre todo dado o persuasivo ${ }^{8}$.

5 CHOUKR, Fauzi Hassan. Medidas cautelares e prisão processual: Comentários à lei 12.403/2011. Rio de Janeiro: Forense, 2011. p. 34.

6 FERRAZ JUNIOR, Tércio Sampaio. Introdução ao Estudo do Direito: Técnica, Decisão, Dominação. 2. ed. Atlas: São Paulo, 1994. p. 345.

7 Ibidem. p. 322.

8 ARISTÓTELES. Arte retórica e arte poética. Trad. Antônio Pinto de Carvalho; Jean Voilquin; Goffredo Telles Júnior. Tecnoprint, 1969. p. 33 
A Retórica consistia na apresentação de provas, que eram classificadas em artificiais e inartificiais. As primeiras eram conhecidas por "genus argificiale" e estava atrelada a produção de provas próprias da retórica. Essas eram divididas em: a) Ethos - provas éticas: que se referiam ao caráter digno de confiança do orador; b) Pathos - provas patéticas: que eram capazes de motivar a sensibilidade do ouvinte; c) Logos - provas reais: que era o efeito baseado na coerência lógica de apresentação da coisa res (indícios, argumentos, exemplos). As que pertenciam ao "genus inartificiale" referiam-se as provas obtidas em elementos materiais, como decisões jurisprudenciais, doutrinas, documentos etc. Deu origem à atual teoria da prova no Direito processual ${ }^{9}$.

Para Atienza, o argumentar está sempre relacionado a uma ação de comunicação, é estar inserido dentro dos jogos de linguagem. Seu sentido é o de sustentar uma tese, fornecendo argumentos para tanto. Consiste em usar de certa forma a linguagem para dar argumentos a favor ou contra determinado ponto de vista. A argumentação dirige-se a um fim. Assim, é necessário distinguir três elementos, quais sejam: as premissas (da onde se parte); a conclusão (onde se chega) e a inferência (a maneira como as premissas e a conclusão estão unidas, a relação entre elas) ${ }^{10}$.

Sobre a proporcionalidade, esta surge juntamente com o Estado Democrático de Direito, produto de revoluções contra o Estado Absolutista (Antigo Regime), com a finalidade de limitar, controlar e dividir o poder estatal ${ }^{11}$. Revolta-se contra o poder do soberano, exigindo-se a observância dos direitos da população.

Atualmente, parte dos magistrados usa em suas decisões argumentos como: "baseado nos princípios da proporcionalidade e da razoabilidade"; “conforme o princípio da proporcionalidade”; "segundo o princípio

9 FERRAZ JUNIOR, Tércio Sampaio. Introdução ao Estudo do Direito: Técnica, Decisão, Dominação. 2. ed. Atlas: São Paulo, 1994. p. 323.

10 ATIENZA, Manuel. O direito como Argumentação. Trad. Manuel Poirier Braz. Lisboa: Escolar Editora, 2004. p. 95-98.

11 FELDENS, Luciano. Direitos Fundamentais e Direito Penal: a Constituição Penal. 2. ed. rev. e ampl. Porto Alegre: Livraria do Advogado Editora, 2012. p. 21. 
da razoabilidade"; "postulado da proporcionalidade" etc. ${ }^{12}$, como se estes argumentos estivessem baseados em um ideal metafísico de justiça do qual a proporcionalidade faria parte ${ }^{13}$. A utilização da proporcionalidade atua como um "coringa" que consegue transformar argumentos abstratos em uma ordem legítima ${ }^{14}$.

[...] a invocação retórica dos princípios como nova panaceia para os problemas constitucionais brasileiros, seja na forma de absolutização de princípios ou na forma da compulsão ponderadora, além de implicar um modelo simplificador, pode servir para o encobrimento estratégico de práticas orientadas à satisfação de interesses avessos à legalidade e à constitucionalidade e, portanto, à erosão continuada da força normativa da Constituição. Antes da ênfase no debate (muitas vezes, estéril) sobre a diferença entre princípios e regras, impõe-se a construção de uma teoria das normas constitucionais que sirva a uma concretização juridicamente consistente e socialmente adequada dos respectivos princípios, regras e híbridos normativos no contexto brasileiro ${ }^{15}$.

Além disso, há ainda aqueles que pensam a proporcionalidade apenas sob o viés de Robert Alexy, focando unicamente nas máximas da adequação, necessidade e proporcionalidade em sentido estrito. É preciso esclarecer que seus estudos sobre a proporcionalidade partem de uma concepção não positivista do Direito, o que permite à moral exercer uma

12 FEDATO, Matheus Arcangelo; KAZMIERCZAK, Luiz Fernando. Análise Crítica da expressão "garantia da ordem pública" na prisão preventiva. Revista da Faculdade de Direito do Sul de Minas, Pouso Alegre, Edição Especial: 41-59, 2019. p. 51.

13 MORAIS, Fausto Santos de. Ponderação e Arbitrariedade: A inadequada recepção de Alexy pelo STF. Salvador: Juspodvm, 2016.

14 "Afirmo que a jurisdição brasileira funciona com base em argumentos de autoridade e, especialmente nos casos controversos, em função da agregação de opiniões individuais. A justificação das decisões articula as razões pelas quais o indivíduo que a redigiu foi convencido desta ou daquela solução e são irrelevantes para o resultado final do julgamento" (RODRIGUEZ, José Rodrigo. Como Decidem as Cortes? Para uma crítica do direito (brasileiro). Rio de Janeiro: FGV Editora, 2013. p. 51).

15 NEVES, Marcelo. Entre Hidra e Hércules: Princípios e regras constitucionais como diferença paradoxal do sistema jurídico. São Paulo: Martins Fontes, 2013. p. 196. 
função corretiva ${ }^{16}$. Nesse ponto é preciso separar os caminhos seguidos por Alexy e os seguidos por este estudo. Entende-se que os ideais de aplicação do Direito dever estar ligados a uma leitura da filosofia da linguagem e da hermenêutica filosófica ${ }^{17}$, conforme a doutrina de Lenio Streck e sua crítica hermenêutica do direito ${ }^{18}$.

Conforme Streck: "Com o giro ontológico operado por Heidegger, se dá - de uma forma inédita em toda tradição filosófica — uma reconciliação entre prática e teoria e, ao mesmo tempo, ocorre um deslocamento do solipsismo subjetivista para um contexto intersubjetivo de fundamentação. Heidegger cria um novo conceito que descreve um ambiente no interior do qual conhecimento prático e conhecimento teórico se relacionam a partir de uma circularidade: o círculo hermenêutico (hermeneutische Zirkel). Há uma espécie de "privilégio" do conhecimento prático em virtude da estrutura do logos hermenêutico"19.

Para tanto, o círculo hermenêutico se torna indispensável. Gadamer coloca o círculo hermenêutico dentro da dialética, na relação entre a parte e o todo, entre o universal e o particular, inserindo-o como condição interpretativa. $\mathrm{O}$ constante movimento do círculo e a abertura para um

16 MORAIS, Fausto Santos de. Ponderação e Arbitrariedade: A inadequada recepção de Alexy pelo STF. Salvador: Juspodvm, 2016. p. 199.

17 "Na verdade, não é a história que nos pertence mas somos nós que pertencemos a ela. Muito antes de nos compreendermos na reflexão sobre o passado, já nos compreendemos naturalmente na família, na sociedade e no Estado em que vivemos. A lente da subjetividade é um espelho deformante. A autorreflexão do indivíduo não passa de uma luz tênue na corrente cerrada da vida histórica. Por isso, os preconceitos de um indivíduo, muito mais que seus juízos, constituem a realidade histórica de seu ser. [...] A compreensão deve ser pensada menos como uma ação da subjetividade e mais como um retroceder que penetra num acontecimento da tradição, onde se intermedeiam constantemente passado e presente. É isso que deve ser aplicado à teoria hermenêutica, que está excessivamente dominada pela ideia dos procedimentos de um método" (GADAMER, Hans-Georg. Verdade e método: traços fundamentais de uma hermenêutica filosófica. Vol. I. Petrópolis: Editora Vozes, 2014. p. 388).

18 STRECK, Lenio Luiz. Hermenêutica Jurídica e $(m)$ Crise: uma exploração hermenêutica da construção do Direito. $3^{\mathrm{a}}$ ed. Porto Alegre: Livraria do Advogado, 2001.

19 STRECK, Lenio. O que é isto - decido conforme minha consciência?. 4.ed.rev. Porto Alegre: Livraria do Advogado Editora, 2013. p. 63. 
novo sentido são essenciais. "O intérprete deverá [...] ter-se com a tradição e, no texto, colocar à prova seus preconceitos para confrontá-los” ${ }^{20}$.

O modelo de argumentativo proposto está ligado à filosofia da linguagem, entendendo-a como essencial para o combate à decisões genéricas. A percepção da pragmática e do modo como o sentido da linguagem é constantemente construído pelo Ser (Dasein) ${ }^{21}$ no mundo se mostra como algo essencial para lidar com decisões jurídicas, as quais estão atreladas aos fatos inseridos nos casos concretos e precisam buscar qual a melhor solução por meio da interpretação da linguagem.

O princípio da proporcionalidade possui elevada influência na temática das prisões cautelares, refletindo acerca dos interesses postos em conflito, como o da eficácia na repressão dos delitos (segurança pública) e a esfera de liberdade do indivíduo. Composto por duas facetas, quais sejam, a proibição do excesso e a proibição da proteção deficiente, a proporcionalidade tenta balizar as divergências do caso concreto, buscando encontrar uma medida que não se revele abusiva e que cumpra sua finalidade.

A proporcionalidade surge com o Estado Democrático de Direito, após o término Estado Absolutista ${ }^{22}$, em um momento de valorização dos direitos humanos, no qual a dignidade humana ganhou extrema importância. Passou-se a exigir da nova ordem constitucional uma concreta proteção dos direitos fundamentais, de modo que as intervenções estatais devem ser adequadas, necessárias e proporcionais.

Tido como um dos princípios fundamentais de um Estado Democrático, a proporcionalidade origina-se na tentativa de frear atos estatais abusivos, visando proteger a população. Decisões executivas, atos legislativos e decisões judiciais direcionados a adoção de medidas que, por excesso, violem direitos fundamentais, devem ser proibidos (Übermassverbot). Dessa forma, não se poderia admitir que o legislador criasse

20 PINHO, Ana Cláudia Bastos de. Para além do garantismo: uma proposta hermenêutica de controle da decisão penal. Belém: UFPA/Instituto de Ciências Jurídicas, 2011. p. 121.

21 HEIDEGGER, Martin. Ser e Tempo. Trad. Fausto Castilho. Campinas: Editora da Unicamp, 2012. p. 81.

22 FELDENS, Luciano. Direitos Fundamentais e Direito Penal: a Constituição Penal. 2. ed. rev. e ampl. Porto Alegre: Livraria do Advogado, 2012. p. 21. 
disposições no Código de Processo Penal determinando a obrigatoriedade da conversão do flagrante em preventiva para todos os casos, ou impor que a prisão preventiva é a regra, relegando as medidas alternativas a um segundo plano.

Para orientar a decretação das prisões cautelares, o artigo 282, incisos I e II, do Código de Processo Penal determina que as medidas cautelares deverão ser aplicadas observando-se: I) a necessidade para aplicação da lei penal, para investigação ou instrução criminal e para evitar a prática de infrações penais; II) a adequação da medida à gravidade do crime, circunstâncias do fato e condições pessoais do acusado ou investigado. Ambas, "necessidade e adequação [...] são os referenciais fundamentais na aplicação das medidas cautelares pessoais no processo penal”³.

Cabe falar que o disposto nos incisos I e II do artigo 282 não expressa essencialmente o que doutrinariamente se conceitua como adequação e necessidade. Costuma-se confundir o disposto no artigo 282 do CPP e o conteúdo das máximas da proporcionalidade. O que o inciso I indica como "necessidade" significa a busca pela finalidade da medida, a quais fins ela se destina a proteger. Assim, finalisticamente a medida deve ser necessária para aplicação da lei penal, para investigação ou instrução criminal e para evitar a prática de infrações penais ${ }^{24}$. Pelo inciso II, objetiva-se a correspondência entre a medida a ser adotada e a pragmática que envolve a situação em análise, que se liga à gravidade do crime, às circunstâncias do fato e às condições pessoais do acusado ou investigado. A gravidade do crime deve ser sempre analisada em concreto. As circunstâncias do fato e as condições pessoais do agente devem corresponder à medida adotada e à finalidade pretendida, deve haver uma correlação.

No Processo Penal, a máxima da adequação determina um olhar para a finalidade da medida, qual seja, a prisão cautelar, buscando analisar se a constrição da liberdade poderá promover o fim buscado pela autoridade coatora, de modo que se não for possível a promoção do fim,

23 OLIVEIRA, Eugênio Pacelli de. Curso de Processo Penal. 18. ed. rev. ampl. e atual. São Paulo: Atlas, 2014.p. 504.

24 Ressalva-se, aqui, a possível violação à presunção de inocência que a finalidade "para evitar a prática de infrações penais" pode acarretar. 
a medida não deve ser tomada. Fabio Delmanto propõe a análise da "adequação qualitativa” e "adequação quantitativa”, exemplificando a primeira da seguinte maneira: "se a finalidade é evitar a fuga do acusado, não há razão para proibi-lo de entrar em contato com determinadas pessoas". Ainda, a medida de prisão não será adequada qualitativamente se a pessoa já houver sido ou poderá ser condenada a pena que não seja de prisão, ou que a cumpra em regime semiaberto ou aberto.

A adequação quantitativa diz respeito a duração e intensidade da medida com relação ao fim pretendido ${ }^{25}$. Assim "se a prisão preventiva foi decretada para a 'conveniência da instrução criminal', deve ela ser revogada tão logo esteja concluída a instrução, salvo se existir outo motivo legal para a manutenção da custódia cautelar" ${ }^{26}$. De outra forma, se houver condenação em primeiro grau, isso não implica que haja prisão automática ou a manutenção da prisão anterior. Para que ocorra a prisão após condenação sem trânsito em julgado, deve haver decisão devidamente fundamentada e presença dos requisitos autorizadores. Cumpre assinalar a imprescindibilidade de se atentar para a sanção cominada para o crime, de forma que se esta não previr pena privativa de liberdade, a prisão cautelar não se mostra adequada, posto que o fim proposto pela norma penal é outro, diverso da prisão, podendo ser aplicadas medidas cautelares alternativas a depender da finalidade almejada. Segundo Badaró:

"Caso o juiz anteveja que a pena a ser imposta será apenas uma pena de multa, ou uma pena privativa de liberdade que será substituída por pena restritiva de direito, ou ainda, uma pena privativa de liberdade que será condicionalmente suspensa (sursis), ou, finalmente, uma pena privativa de liberdade a ser cumprida em regime aberto, será ilegal a decretação da prisão preventiva, posto que desproporcional ao resultado final do processo cuja utilidade se quer assegurar. Se a medida cautelar, no caso a prisão preventiva, for mais gravosa que a pena a ser ao final imposta, não será dotada do caráter de instrumentalidade e acessoriedade inerentes à tutela cautelar. Mesmo no que diz respeito à provisoriedade, não

${ }_{25}$ Relaciona-se com a provisionalidade e a provisoriedade.

26 DELMANTO, Fabio Machado de Almeida. Medidas substitutivas e alternativas à prisão cautelar. Rio de Janeiro: Renovar, 2008. p. 67. 
se pode admitir que a medida provisória seja mais severa que a medida definitiva que a irá substituir e a qual ela deve preservar" ${ }^{27}$.

Ainda, existe a necessidade de o juiz observar os crimes cometidos sem violência ou grave ameaça à pessoa, em que a pena será ao final substituída por restritiva de direitos ${ }^{28}$. No tocante à máxima da necessidade, esta deve ser entendida como o processo de escolha do meio menos gravoso para atingir a finalidade desejada. Dessa maneira, "um ato estatal que limita um direito fundamental é somente necessário caso a realização do objetivo perseguido não possa ser promovida, com a mesma intensidade, por meio de outro ato que limite, em menor medida, o direito fundamental atingido" ${ }^{29}$. Alguns a nomeiam a máxima da necessidade como "princípio da menor ingerência possível” ${ }^{30}$, de "intervenção mínima" ou de "subsidiariedade" 31 . Tais nomenclaturas exprimem o mesmo significado, que é a adoção da medida menos arbitrária dentre as possíveis.

O artigo 282, $\S 6^{\circ}$, do CPP determina que a prisão preventiva somente será utilizada quando sua substituição não for cabível por nenhuma outra medida cautelar. Portanto, "a regra deverá ser a imposição preferencial das medidas cautelares, deixando a prisão preventiva para casos de maior gravidade" ${ }^{2}$. Interessante exemplo da desnecessidade da prisão preven-

27 Conclui o autor da seguinte maneira: "Se não se projeta uma pena privativa de liberdade a ser cumprida no cárcere, diante da provável condenação, é ilegal a decretação da prisão preventiva, posto que incompatível com a natureza cautelar de tal medida. Deve haver uma proporcionalidade entre a pena que se prevê como provável em caso de condenação e a gravidade da medida cautelar a ser imposta ao acusado”. (BADARÓ, Gustavo Henrique Righi Ivahy. A prisão preventiva e o princípio da proporcionalidade: proposta de mudanças legislativas. Revista da Faculdade de Direito da Universidade de São Paulo. v. 103, p. 381 - 408, jan./dez. 2008. p. 397).

LOPES JUNIOR, Aury. Prisões Cautelares. 4.ed.rev.atual e ampl. São Paulo: Saraiva, 2013. p. 47. SILVA, Virgílio Afonso da. O proporcional e o razoável. Revista dos Tribunais, São Paulo, n. 798, p. 23-50, 2002. p. 16-17. CANOTILHO, José Joaquim Gomes. Direito constitucional. 7.ed. Coimbra: Livraria Almedina, 2003. p. 270.

31 DELMANTO, Fabio Machado de Almeida. Medidas substitutivas e alternativas à prisão cautelar. Rio de Janeiro: Renovar, 2008. p. 69.

32 OLIVEIRA, Eugênio Pacelli de. Curso de Processo Penal. 18. ed. rev. ampl. e atual. São Paulo: Atlas, 2014. p. 504. 
tiva pode ser encontrado no HC 80.719-4/SP, de relatoria do Ministro Celso de Mello, que assinala: “A privação cautelar da liberdade individual reveste-se de caráter excepcional, somente devendo ser decretada em situações de absoluta necessidade". Nessa linha, continua dizendo que "a prisão preventiva não pode - e não deve - ser utilizada, pelo Poder Público, como instrumento de punição antecipada daquele a quem se imputou a prática do delito". Mais adiante, assevera: “O estado de comoção social e de eventual indignação popular, motivado pela repercussão da prática da infração penal, não pode justificar, só por si, a decretação da prisão cautelar do suposto autor do comportamento delituoso"33.

A terceira fase da aplicação do princípio da proporcionalidade é conhecida como proporcionalidade em sentido estrito. Nessa etapa, presume-se que todos os meios escolhidos são adequados, e que realizam o fim pela menor ingerência possível, restando agora analisar se a medida indicada é mais severa que a finalidade pretendida pela norma. "Quanto maior for o grau de não satisfação ou de afetação de um princípio, tanto maior terá que ser a importância da satisfação do outro" ${ }^{34}$. Busca-se estabelecer limites entre os fins almejados e os meios escolhidos. A escolha da medida não deve ser mais grave do que a finalidade da norma. Basicamente, "deve haver uma proporcionalidade entre a pena que se prevê como provável em caso de condenação e a gravidade da medida cautelar a ser imposta ao acusado" ${ }^{35}$. Sobre a afinidade entre proporcionalidade e Processo Penal, Eugênio Pacelli discorre da seguinte maneira:

Em relação a um possível confronto entre o princípio da inocência (estado ou situação jurídica de inocência) e o da efetividade da jurisdição penal [...] pode ser que se apresente a possibilidade de uma ponderação feita nesses moldes, desde que a pressuposta

33 BRASIL. HC 80719. Relator(a): Min. CELSO DE MELLO, Segunda Turma, julgado em 26/06/2001, DJ 28-09-2001 PP-00037 EMENT VOL-02045-01 PP-00143.

34 ALEXY, Robert. Teoria dos direitos fundamentais. 2.ed. Trad. Virgílio Afonso da Silva. São Paulo: Malheiros Editores, 2012. p. 593.

35 BADARÓ, Gustavo Henrique Righi Ivahy. A prisão preventiva e o princípio da proporcionalidade: proposta de mudanças legislativas. Revista da Faculdade de Direito da Universidade de São Paulo. v. 103, p. 381 - 408, jan./dez. 2008. p. 397. 
fundamentação cautelar da prisão em determinado caso concreto. A ponderação, então, far-se-ia pelo exame da adequação da medida, quando a prisão deveria ser justificada com relação aos escopos do processo; de sua necessidade, pela apreciação da relação entre a prisão e sua motivação (risco de fuga, intimidação de testemunhas etc.), e de sua proporcionalidade em sentido estrito, isto é, pelo exame da gravidade da prisão cautelar em relação à pena abstratamente cominada ao tipo penal, bem como a viabilidade de sua aplicação no caso concreto (condições pessoais do agente, natureza da infração, análise da culpabilidade etc. ${ }^{36}$.

Caberia falar aqui na observância da pena cominada ao delito e o tempo da medida cautelar, a fim de averiguar se a medida não está sendo mais gravosa do que a própria pena em abstrato a ser aplicada ou a pena previsivelmente aplicável ${ }^{37}$. As duas primeiras máximas trabalham com os meios a serem utilizados, já a terceira, com o fim perseguido. A análise se dá pela utilização de um meio apto e que menos ingerência cause, devendo esse ser justificado com base na finalidade pretendida. Alexy emprega na terceira fase a ponderação, balizando o conflito entre princípios atribuindo à moral uma função corretiva. Por isso, entende-se que a construção do discurso baseado na proporcionalidade deve seguir-se pela hermenêutica filosófica ${ }^{38}$. A análise entre fins e meios deve dar-se pela filosofia da linguagem, em que a sintática, a semântica e a pragmática tem grande importância.

A construção argumentativa da decisão deve organizar corretamente os elementos da linguagem (sintaxe), de forma com que as disposições legais estejam em consonância com o sistema. A relação entre as normas da Constituição, do Código de Processo Penal e das leis especiais

36 OLIVEIRA, Eugênio Pacelli de. Processo e Hermenêutica na tutela penal dos direitos fundamentais. 3. ed. rev. e atual. São Paulo: Editora Atlas, 2012. p. 133.

37 Existe discussão acerca de o parâmetro ser a pena cominada em abstrato ao delito e a pena previsivelmente aplicável. Como essa discussão não é objeto do presente trabalho, remete-se o leitor para: DELMANTO, Fabio Machado de Almeida. Medidas substitutivas e alternativas à prisão cautelar. Rio de Janeiro: Renovar, 2008. p. 70.

38 MORAIS, Fausto Santos de. Ponderação e Arbitrariedade: A inadequada recepção de Alexy pelo STF. Salvador: Juspodvm, 2016. p. 220. 
e a Constituição deve ocorrer sem contradições ${ }^{39}$. A justificação externa das decisões deve levar em conta o aspecto material (semântico). Nesse sentido, o teor da expressão "garantia da ordem pública”, por exemplo, não pode abarcar os significados de gravidade abstrata do delito, clamor social, acautelamento do meio social, abalo social, preservação das instituições públicas e risco de reiteração delitiva. Sobre esse ponto, leciona Luigi Ferrajoli,

Um argumento no qual se baseiam muitos defensores da prisão preventiva é o clamor social originado pela ideia de que um delinquente ainda não julgado não seja punido imediatamente. Pode ocorrer que nisso haja algo de verdade: uma parte da opinião pública seguramente associa finalidades diretamente repressivas à prisão preventiva. Mas essa ideia primordial do bode expiatório é justamente uma daquelas contra a qual nasceu aquele delicado mecanismo que é o processo penal, que não serve, como já afirmei, para proteger a maioria, mas sim para proteger, ainda que contra a maioria, aqueles cidadãos individualizados que, não obstante suspeitos, não podem ser ditos culpados sem provas ${ }^{40}$.Na mesma linha, Ferrajoli diz ainda que "de hecho, peligrosidad e sospecha son, por su naturaliza, incompatibles com las exigencias de la estricta legalidade [...] dejan espacio a medidas em blanco basadas em valoraciones tan opinables como incontrolabes" ${ }^{41}$. Para o autor, expressões de ordem abstrata vão contra a estrita legalidade e acabam sendo incompatíveis com um Estado Democrático de Direito.

Deve haver correlação entre a medida adotada e a finalidade pretendida, não sendo correto proibir o acesso a determinados lugares

39 "Concebido como um objeto de desejo o Código de Processo Penal incorpora as redes sociais mobilizadas em torno da manutenção do poder e assim estabelece o diálogo entre a tradição autoritária inautêntica e a efetivação de um modelo de compreensão adequado ao projeto político democrático inscrito na Constituição de 1988”. (PRADO, Geraldo; MELCHIOR, Antonio Pedro. Breve análise crítica da lei n. 12.403, de 2011, que modifica o regime das cautelares pessoais no processo penal brasileiro. Boletim IBCCRIM, Ano 19, No 223, Junho 2011. p. 10).

40 FERRAJOLI, Luigi. Direito e razão: teoria do garantismo penal. São Paulo: Editora Revista dos Tribunais, 2002. p. 450.

41 FERRAJOLI, Luigi. El garantismo y la filosofía del derecho. Bogotá: Universidad Externado de Colombia, 2000. p. 104. 
que não tem ligação com o crime imputado. Devem ser sempre levados em conta os elementos da lógica para explicitar as deduções feitas na decisão. A argumentação pragmática vai envolver todos os elementos do caso concreto, com o objetivo de estabelecer em que sentido uma medida se mostra como um meio adequado e como uma finalidade necessária para a proteção de um bem determinado.

Aqui entram todas as circunstâncias em que foi cometido o crime, as condições do agente, a gravidade das medidas e a possibilidade de sua aplicação. Cria-se um círculo hermenêutico em que o intérprete da norma vai dialogar consigo mesmo e com o mundo, buscando a decisão que deve tomar. Portanto, para a aplicação do Direito em uma decisão judicial é necessário levar em conta os como os três níveis da linguagem, bem como a proporcionalidade na proteção de direitos fundamentais, operam dentro dessa temática específica, permitindo que a construção do discurso seja adequada.

\section{Como construir argumentativamente uma decisão QUE DECRETA OU MANTÉM PRISÕES CAUTELARES NO PROCESSO PENAL?}

Em primeiro lugar é importante notar que o dever de fundamentação das decisões judiciais, ou de qualquer ato do Poder Público, está previsto constitucionalmente no artigo 93, IX da Constituição Federal, que diz: "todos os julgamentos dos órgãos do Poder Judiciário serão públicos, e fundamentadas todas as decisões, sob pena de nulidade”. Em complementação ao disposto pela Constituição estão o artigo 564, V, do Código de Processo Penal, que trata das nulidades e que prevê sua ocorrência quando houver decisão carente de fundamentação, o artigo 283 do CPP, dizendo que ninguém poderá ser preso senão em flagrante delito ou por ordem escrita e fundamentada da autoridade judiciária competente, em decorrência de prisão cautelar ou em virtude de sentença condenatória transitada em julgado, e o artigo 315, também do CPP, que determina que a decisão que decretar, substituir ou denegar a prisão preventiva será sempre motivada e fundamentada.

Diante da aprovação da chamada da Lei "Anticrime" (Lei ${ }^{\circ}$ 13.964/2019), foram inseridos dois parágrafos no art. 315 do Código de Processo Penal que buscam evitar decisões genéricas e sem a devida 
fundamentação, fazendo com que o magistrado cumpra com seu dever constitucional de fundamentação. ${ }^{42}$ Segundo Atienza:

"O Estado constitucional pressupõe assim um desenvolvimento no que tange à tarefa justificativa dos órgãos públicos e, portanto, uma maior exigência de argumentação jurídica [...] o ideal do Estado constitucional (o culminar do Estado de Direito) pressupõe a subordinação completa do poder ao Direito e à razão: a força da razão, frente à razão da força. Parece por isso bastante lógico que a evolução do Estado constitucional tenha sido acompanhada de um incremento quantitativo e qualitativo de exigência de fundamentação das decisões dos órgãos públicos”³.

A Lei $\mathrm{n}^{\mathrm{0}}$ 13.964/2019 também alterou o artigo 312, $\S 2^{\mathrm{ou4}}$, que passa a exigir a existência concreta de fatos novos ou contemporâneos

42 “Art. 315. A decisão que decretar, substituir ou denegar a prisão preventiva será sempre motivada e fundamentada.

$\S 1^{\circ} \mathrm{Na}$ motivação da decretação da prisão preventiva ou de qualquer outra cautelar, o juiz deverá indicar concretamente a existência de fatos novos ou contemporâneos que justifiquem a aplicação da medida adotada.

$\S 2^{\circ}$ Não se considera fundamentada qualquer decisão judicial, seja ela interlocutória, sentença ou acórdão, que:

I - limitar-se à indicação, à reprodução ou à paráfrase de ato normativo, sem explicar sua relação com a causa ou a questão decidida;

II - empregar conceitos jurídicos indeterminados, sem explicar o motivo concreto de sua incidência no caso;

III - invocar motivos que se prestariam a justificar qualquer outra decisão;

IV - não enfrentar todos os argumentos deduzidos no processo capazes de, em tese, infirmar a conclusão adotada pelo julgador;

V - limitar-se a invocar precedente ou enunciado de súmula, sem identificar seus fundamentos determinantes nem demonstrar que o caso sob julgamento se ajusta àqueles fundamentos;

VI - deixar de seguir enunciado de súmula, jurisprudência ou precedente invocado pela parte, sem demonstrar a existência de distinção no caso em julgamento ou a superação do entendimento." (NR)

43 ATIENZA, Manuel. O direito como Argumentação. Trad. Manuel Poirier Braz. Lisboa: Escolar Editora, 2004. p. 23.

44 “Art. $312, \S 2^{\circ}$ : A decisão que decretar a prisão preventiva deve ser motivada e fundamentada em receio de perigo e existência concreta de fatos novos ou contemporâneos que justifiquem a aplicação da medida adotada”. 
que justifiquem a adoção da prisão preventiva e o artigo $313, \S 2^{045}$, o qual não admite a prisão preventiva com caráter de antecipação de pena ou como decorrência imediata da investigação criminal ou recebimento da denúncia. Ainda, o artigo 316, parágrafo único ${ }^{46}$, passa a exigir a revisão da necessidade de manutenção da cautelar a cada 90 dias, sob pena de a prisão se tornar ilegal.

Cumpre dizer que as alterações promovidas no Código de Processo Penal pela lei citada, no que tange ao escopo da pesquisa, vão ao encontro do que propõe o presente trabalho, sempre no intuito de proteção dos direitos fundamentais.

A proposta da pesquisa baseia-se no garantismo penal de Luigi Ferrajoli, o qual busca a promoção dos direitos fundamentais, a liberdade dos cidadãos e a limitação do poder estatal. Uma nação democrática deve zelar pelos valores constitucionais, dando espaço para manifestação de minorias, as quais, muitas vezes, sofrem com as mazelas sociais e do processo penal ${ }^{47}$. Na definição de Ferrajoli, o garantismo designa:

"[...] um modelo normativo de direito: precisamente, no que diz respeito ao direito penal, o modelo de "estrita legalidade", próprio do Estado de Direito, que sob o plano epistemológico se caracteriza como um sistema cognitivo ou de poder mínimo, sob o plano político se caracteriza como uma técnica de tutela idônea a minimizar a violência e maximizar a liberdade e, sob o plano jurídico, como

45 “Art. 313, § 2º Não será admitida a decretação da prisão preventiva com a finalidade de antecipação de cumprimento de pena ou como decorrência imediata de investigação criminal ou da apresentação ou recebimento de denúncia”.

46 “Art. 316. Parágrafo único: Decretada a prisão preventiva, deverá o órgão emissor da decisão revisar a necessidade de sua manutenção a cada 90 (noventa) dias, mediante decisão fundamentada, de ofício, sob pena de tornar a prisão ilegal”.

47 “[...] el garantismo constitucional [...] ha ido expandiéndose históricamente y aún puede seguir haciéndolo, a tenor de las concretas necesidades incorporadas en él como derechos fundamentales, avanzando en diversas direcciones: en la tutela tanto de los derechos sociales como de los derechos de libertad; frente a los poderes privados y frente a los poderes públicos; en el plano internacional y en el estatal”. (FERRAJOLI, Luigi. Garantismo: Debate sobre el derecho y la democracia. Trad. Andrea Greppi. Madrid: Editorial Trotta, 2006. p. 42). 
um sistema de vínculos impostos à função punitiva do Estado em garantia dos direitos dos cidadãos. É consequentemente, "garantista" todo sistema penal que se conforma normativamente com tal modelo e que o satisfaz efetivamente." ${ }^{48}$

Uma leitura do garantismo penal a partir da hermenêutica filosófica é salutar e capaz de promover de uma maneira mais adequada de aplicação do garantismo. Nesse sentido, Ana Cláudia Bastos de Pinho aponta para os limites da teoria de Ferrajoli ao aceitar a discricionariedade judicial na aplicação do direito pela ponderação de valores. Assim,

“[...] por mais que se admita a preocupação da teoria do garantismo penal com a tutela dos direitos fundamentais, o problema [...] referente à aceitação da discricionariedade ameaça o conteúdo democrático da própria teoria. Em outras palavras, o resultado de uma decisão garantista pode, de fato, proteger os direitos individuais do imputado, porém, nem sempre, o caminho percorrido estará constante com os princípios democráticos. O fantasma da discricionariedade ou decisionismo e a artificialidade da teoria podem tirar o garantismo da trilha". ${ }^{49}$

Com o intuito de exemplificar um modo de responder a pergunta "Como construir argumentativamente uma decisão que decreta ou mantém prisões cautelares no Processo Penal?”, apresenta-se um quadro composto por axiomas, similar aos propostos pela teoria do garantismo penal de Luigi Ferrajoli ${ }^{50}$, que expressam a negativa da pergunta acima feita, qual seja, "Como não argumentar em uma decisão que decreta ou mantém prisões cautelares no Processo Penal”. O quadro é exemplificativo e não exauriente, e busca ilustrar (sistematizar) o que com esse trabalho foi proposto em forma de conclusões preliminares. Os axiomas abaixo não pretendem ser respostas antes das perguntas nem regras positivadas para

48 FERRAJOLI, Luigi. Direito e razão: teoria do garantismo penal. São Paulo: Editora Revista dos Tribunais, 2002. p. 684.

49 PINHO, Ana Cláudia Bastos de. Para além do garantismo: uma proposta hermenêutica de controle da decisão penal. Belém: UFPA/Instituto de Ciências Jurídicas, 2011. p. 147.

50 FERRAJOLI, Luigi. Direito e razão: teoria do garantismo penal. São Paulo: Editora Revista dos Tribunais, 2002. p. 74-75. 
a aplicação prática. A opção por esse modelo é ilustrativa e atua como forma de demonstrar as observações realizadas durante a pesquisa ${ }^{51}$.

Quanto à fundamentação da decisão que decreta ou mantém as prisões cautelares, entende-se que devem ser observados os seguintes axiomas:

Nula a argumentação que se baseie em critérios abstratos, conceitos indeterminados ou diversos daqueles previstos pela legislação competente;

Nula a argumentação que se basear unicamente no paradoxo Segurança Pública x Liberdade Individual para decretar ou manter prisão preventiva;

Nula a argumentação que faça referência exclusivamente à ponderação abstrata de princípios para decretar ou manter prisão preventiva;

51 Nessa linha, também é possível observar o artigo 489, §1º do Código de Processo Civil, que estabelece os requisitos essenciais para uma decisão judicial ser considerada justificada, delimitando os pontos necessários a serem observados para um provimento adequadamente fundamentado. $\mathrm{O}$ dispositivo determina que não se considerará fundamentada qualquer decisão judicial, seja ela interlocutória, sentença ou acórdão, que:

I - se limitar à indicação, à reprodução ou à paráfrase de ato normativo, sem explicar sua relação com a causa ou a questão decidida;

II - empregar conceitos jurídicos indeterminados, sem explicar o motivo concreto de sua incidência no caso;

III - invocar motivos que se prestariam a justificar qualquer outra decisão;

IV - não enfrentar todos os argumentos deduzidos no processo capazes de, em tese, infirmar a conclusão adotada pelo julgador;

$\mathrm{V}$ - se limitar a invocar precedente ou enunciado de súmula, sem identificar seus fundamentos determinantes nem demonstrar que o caso sob julgamento se ajusta àqueles fundamentos;

VI - deixar de seguir enunciado de súmula, jurisprudência ou precedente invocado pela parte, sem demonstrar a existência de distinção no caso em julgamento ou a superação do entendimento.

$\S 2^{\circ}$ No caso de colisão entre normas, o juiz deve justificar o objeto e os critérios gerais da ponderação efetuada, enunciando as razões que autorizam a interferência na norma afastada e as premissas fáticas que fundamentam a conclusão. BRASIL. Lei no 13.105/2016 - Código de Processo Civil. Brasília, Distrito Federal: Senado, 2016. 
Nula a argumentação que apenas fizer menção à proporcionalidade e à razoabilidade para decretar ou manter prisão preventiva sem correlacioná-las com o caso concreto, demonstrando objetivamente sua incidência;

Nula a argumentação que apele para argumentos de ordem moral, de grau subjetivo ou discricionário, exteriorizando na decisão tão somente a concepção pessoal do julgador sobre o caso;

Nula a argumentação que não se baseie em dados objetivos relacionados ao caso, considerando tão somente premissas ou pressuposições de ordem abstrata e genérica;

Nula a argumentação que se refira unicamente ao requisito legal da garantia da ordem pública ou da ordem econômica;

Nula a argumentação que fundamente a garantia da ordem pública com base no clamor público, acautelamento do meio social, abalo social, gravidade em abstrato do crime, preservação das instituições públicas e risco de reiteração delitiva;

Nula a argumentação que fundamente a prisão preventiva na possibilidade de reiteração delitiva sem que demonstre incabível a aplicação de medida cautelar diversa da prisão;

Nula a argumentação que fundamente a garantia da ordem econômica em presunções de dano;

Nula a argumentação que determine a prisão preventiva sob o pretexto de assegurar a instrução penal sem que demonstre incabível a aplicação de medida cautelar diversa da prisão;

Nula a argumentação que sustente a prisão preventiva sob o pretexto de assegurar a instrução penal com base no perigo de o investigado ou acusado apagar provas ou coagir testemunhas ou oficiais sem que seja demonstrada a inadequação da aplicação de medida cautelar diversa da prisão;

Nula a argumentação que determine a prisão preventiva sob o pretexto de assegurar a aplicação da lei penal sem que se demonstre incabível a aplicação de medida cautelar diversa da prisão;

Nula a argumentação que determine a prisão preventiva sob o pretexto de assegurar a aplicação da lei penal com base no perigo de o investigado ou acusado fugir ou se evadir do distrito 
da culpa sem que seja demonstrada a inadequação da aplicação de medida cautelar diversa da prisão;

No que se refere às medidas cautelares alternativas à prisão, objetiva-se este modelo:

Nula a argumentação que considere incabível medida cautelar diversa da prisão sem que demonstre de forme exauriente sua inadmissibilidade;

Nula a argumentação que negue medida cautelar diversa por alguma impossibilidade a priori de sua efetivação (falta de recursos ou estrutura) sem antes verificar a possibilidade de substituição por outra cautelar;

Nula a argumentação que negue medida cautelar diversa da prisão baseada na periculosidade abstrata do acusado;

Nula a argumentação que negue medida cautelar diversa da prisão baseada na gravidade abstrata do delito;

Nula a argumentação que atribua ao acusado o excesso de prazo na prisão preventiva sem que este o tenha dado causa;

Nula a manutenção da prisão preventiva se houver excesso de prazo e o acusado não tiver responsabilidade por sua causa;

Nula a argumentação que atribua o excesso de prazo ao acusado exclusivamente pela complexidade do processo;

Nula a argumentação que cumule mais de uma medida cautelar sem demonstrar a necessidade de sua incidência;

Nula a manutenção da medida cautelar quando não houver motivos para que esta subsista;

Nula a decisão que não observar as hipóteses de substituição da prisão preventiva em prisão domiciliar, nos termos do artigo 318 do Código de Processo Penal;

Nula a imposição de medidas cautelares diversas sem que seja a medida imposta adequada aos fins do caso concreto (É inadequada a medida que seja inapta a promover a finalidade exigida no caso concreto);

Nula a proibição de frequentar determinados lugares que não estejam de alguma maneira ligados com o fato; 
Nula a proibição de manter contato com determinada pessoa que não esteja de alguma maneira ligada com o fato;

Nula a proibição de ausentar-se da Comarca sem que haja necessidade para a investigação ou instrução;

Nula a proibição de ausentar-se da Comarca sem que a proibição esteja de alguma maneira ligada com o fato (p. ex. trabalho inerente a viagens);

Nula a suspensão do exercício de função pública ou de atividade financeira ou econômica quando o fato com elas não estiver relacionado;

Nula a internação provisória do acusado nas hipóteses de crimes praticados com violência ou grave ameaça, quando os peritos concluírem ser inimputável ou semi-imputável sem que haja comprovação da inimputabilidade ou semi-imputabilidade e não houver sido demonstrado o risco concreto de reiteração criminosa;

Nula a imposição de fiança para assegurar o comparecimento aos atos do processo, tendo em vista a não obrigatoriedade de participação do réu, presumidamente inocente e sem ônus de prova, nos atos processuais;

Nula imposição de fiança quando não haja risco de obstrução do processo;

Nula a argumentação que imponha monitoração eletrônica com base apenas no perigo abstrato de que o réu ofereça risco à instrução criminal, à aplicação da lei penal e no risco de reiteração criminosa.

No que se refere às Prisões Cautelares, de modo geral, objetiva-se este modelo: Nula imposição de prisão cautelar sem fundamentação;

Nula fundamentação sem estarem presentes os pressupostos de prova de existência do crime e de indícios suficientes de autoria (inclusive para medidas cautelares alternativas à prisão);

Nula fundamentação sem adequação da medida cautelar ao caso concreto;

Nula adequação da medida cautelar ao caso concreto sem apropriação da medida à gravidade do crime, às circunstâncias do fato e às condições pessoais do indiciado ou acusado; 
Nula fundamentação sem demonstração da necessidade da medida cautelar no caso concreto;

Nula necessidade sem risco objetivamente demonstrado para a aplicação da lei penal, para a investigação ou a instrução criminal, para evitar a prática de infrações penais ou quando imprescindível para as investigações do inquérito policial;

Nulo risco se demonstrada a suficiência das medidas cautelares alternativas à prisão;

Nula suficiência das medidas alternativas se isolada ou cumulativamente não eliminarem ou reduzirem o risco das hipóteses que ensejam prisão cautelar.

No que se refere às Prisões Temporárias, objetiva-se este modelo:

Nula prisão temporária quando suficiente outra medida cautelar alternativa;

Nula prisão temporária sem fundamentação;

Nula fundamentação sem adequação da prisão temporária ao caso concreto;

Nula adequação da prisão temporária ao caso concreto sem apropriação da medida à gravidade do crime, às circunstâncias do fato e às condições pessoais do indiciado ou acusado;

Nula adequação fora das hipóteses legais (Lei no 7.960/89);

Nula adequação quando não houver fundadas razões de autoria e participação nos crimes indicados no inciso III do artigo $1^{\circ}$ da Lei $n^{0} 7.960 / 89$, acrescida da não-identificação ou falta de residência (inciso II), como indício de que o investigado não possa mais ser encontrado, vindo a frustrar a aplicação da lei penal (inciso I);

Nula fundamentação sem demonstração da necessidade da prisão temporária;

Nula necessidade sem risco objetivamente demonstrado para as investigações do inquérito policial;

Nulo risco se demonstrada a suficiência das medidas cautelares alternativas à prisão;

Nula suficiência das medidas alternativas se isolada ou cumulativamente não eliminarem ou reduzirem o risco das hipóteses que ensejam prisão temporária. 
No que se refere às Prisões Preventivas, objetiva-se este modelo:

Nula prisão preventiva quando suficiente outra medida cautelar alternativa;

Nula prisão preventiva sem fundamentação;

Nula fundamentação sem adequação da prisão preventiva ao caso concreto;

Nula adequação da prisão preventiva ao caso concreto sem apropriação da medida à gravidade do crime, às circunstâncias do fato e às condições pessoais do indiciado ou acusado;

Nula adequação fora das hipóteses legais (Art. 312 e 313, CPP);

Nula adequação sem previsão de prisão penal com cominação de pena privativa de liberdade em crimes dolosos punidos com pena máxima superior a 4 anos, sem condenação por outro crime doloso com sentença transitada em julgado, sem envolver violência doméstica e familiar, para garantir a execução das medidas protetivas de urgência ou sem haver dúvidas sobre a identificação civil;

Nula adequação se a prisão preventiva não consistir em meio hábil;

Nulo meio hábil (a prisão preventiva não consiste em meio hábil) para crimes culposos, contravenções, punidos com penas restritivas de direito, com pena de multa, com detenção (Art. 213, § $1^{\circ}$ );

Nula fundamentação sem demonstração da necessidade da prisão preventiva;

Nula necessidade sem risco objetivamente demonstrado para a aplicação da lei penal, para a investigação ou a instrução criminal ou para evitar a prática de infrações penais;

Nulo risco se demonstrada a suficiência das medidas cautelares alternativas à prisão;

Nula suficiência das medidas alternativas se isolada ou cumulativamente não eliminarem ou reduzirem o risco das hipóteses que ensejam prisão preventiva; 


\section{ConsideraçõEs finaIS}

O princípio da proporcionalidade possui elevada influência na temática das prisões cautelares, refletindo acerca dos interesses postos em conflito, como o da eficácia na repressão dos delitos (segurança pública) e a esfera de liberdade do indivíduo. Composto por duas facetas, quais sejam, a proibição do excesso e a proibição da proteção deficiente, a proporcionalidade tenta balizar as divergências do caso concreto, buscando encontrar uma medida que não se revele abusiva e que cumpra sua finalidade.

No sentido de preservação dos direitos fundamentais, ela busca analisar as relações entre os meios e os fins para verificar se houve violação a algum direito. A teoria de destaque sobre a proporcionalidade é a de Alexy, que serviu como grande base para a pesquisa. Com as máximas da adequação e necessidade, permite o exame dos meios utilizados e sua viabilidade. Na proporcionalidade em sentido estrito, procede a uma valoração para analisar se os meios utilizados justificam os fins almejados. Nesse ponto, afasta-se dessa teoria. Entende-se que esse procedimento permite a utilização de uma alta carga moral que se distancia daquilo que é pretendido pelo trabalho. Exalta-se que essa verificação deve se dar pela hermenêutica filosófica, juntamente com os três níveis da linguagem.

A máxima da adequação determina um olhar para a finalidade da medida, qual seja, a prisão cautelar, buscando analisar se a constrição da liberdade poderá promover o fim buscado pela autoridade coatora, de modo que se não for possível a promoção do fim, a medida não deve ser tomada. Cumpre assinalar a imprescindibilidade de se atentar para a sanção cominada para o crime, de forma que se esta não previr pena privativa de liberdade, a prisão cautelar não se mostra adequada, posto que o fim proposto pela norma penal é outro, diverso da prisão.

No tocante à máxima da necessidade, esta deve ser entendida como o processo de escolha do meio menos gravoso para atingir a finalidade desejada. A prisão só será necessária se o objetivo buscado não puder ser atingido por outra medida menos gravosa. Na terceira fase na aplicação do princípio da proporcionalidade (proporcionalidade em 
sentido estrito), presume-se que todos os meios escolhidos são adequados, e que realizam o fim pela menor ingerência possível, restando agora analisar se a medida indicada é mais severa que a finalidade pretendida pela norma. Caberia falar aqui na observância da pena cominada ao delito e o tempo da medida cautelar, a fim de averiguar se a medida não está sendo mais gravosa do que a própria pena em abstrato a ser aplicada ou a pena previsivelmente aplicável. A análise se dá pela utilização de um meio apto e que menos ingerência cause, devendo esse ser justificado com base na finalidade pretendida.

Conclui-se pela necessária utilização da proporcionalidade sob o viés da hermenêutica filosófica pela decisão que decreta ou mantém prisões cautelares, com a finalidade da preservação de direitos fundamentais, seguindo-se a linha do garantismo penal. É sempre necessário atentar-se para a gravidade da medida imposta e o fim que ela procura tutelar. Não se deve admitir medidas inadequadas, desnecessárias ou extremamente gravosas, devendo-se observar as circunstâncias concretas do fato, sendo incabíveis motivações genéricas e abstratas.

\section{REFERÊNCIAS}

ALEXY, Robert. Teoria dos direitos fundamentais. 2.ed. Trad. Virgílio Afonso da Silva. São Paulo: Malheiros Editores, 2012.

ARISTÓTELES. Arte retórica e arte poética. Trad. Antônio Pinto de Carvalho; Jean Voilquin; Goffredo Telles Júnior. Tecnoprint, 1969.

ATIEnZA, Manuel. O direito como Argumentação. Trad. Manuel Poirier Braz. Lisboa: Escolar Editora, 2004.

BADARÓ, Gustavo Henrique Righi Ivahy. A prisão preventiva e o princípio da proporcionalidade: proposta de mudanças legislativas. Revista da Faculdade de Direito da Universidade de São Paulo. v. 103, p. 381 - 408, jan./dez. 2008.

CANOTILHO, José Joaquim Gomes. Direito constitucional. 7.ed. Coimbra: Livraria Almedina, 2003.

CHOUKR, Fauzi Hassan. Medidas cautelares e prisão processual: Comentários à lei 12.403/2011. Rio de Janeiro: Forense, 2011. 
DELMANTO, Fabio Machado de Almeida. Medidas substitutivas e alternativas à prisão cautelar. Rio de Janeiro: Renovar, 2008.

FEDATO, Matheus Arcangelo; KAZMIERCZAK, Luiz Fernando. Análise Crítica da expressão "garantia da ordem pública" na prisão preventiva. Revista da Faculdade de Direito do Sul de Minas, Pouso Alegre, Edição Especial: 41-59, 2019. ISSN: 2447-8709.

FELDENS, Luciano. Direitos Fundamentais e Direito Penal: a Constituição Penal. 2. ed. rev. e ampl. Porto Alegre: Livraria do Advogado Editora, 2012.

FERRAJOLI, Luigi. Direito e razão: teoria do garantismo penal. São Paulo: Editora Revista dos Tribunais, 2002.

FERRAJOLI, Luigi. El garantismo y la filosofía del derecho. Bogotá: Universidad Externado de Colombia, 2000.

FERRAJOLI, Luigi. Garantismo: Debate sobre el derecho y la democracia. Trad. Andrea Greppi. Madrid: Editorial Trotta, 2006.

FERRAZ JUNIOR, Tércio Sampaio. Introdução ao Estudo do Direito: Técnica, Decisão, Dominação. 2. ed. Atlas: São Paulo, 1994.

GADAMER, Hans-Georg. Verdade e método: traços fundamentais de uma hermenêutica filosófica. Vol. I. Petrópolis: Editora Vozes, 2014.

HEIDEGGER, Martin. Ser e Tempo. Trad. Fausto Castilho. Campinas: Editora da Unicamp, 2012.

LOPES JUNIOR, Aury. Prisões Cautelares. 4.ed.rev.atual e ampl. São Paulo: Saraiva, 2013.

LOPES JUNIOR, Aury. Direito Processual Penal. 12. ed. São Paulo: Saraiva, 2015.

MORAIS, Fausto Santos de. Ponderação e Arbitrariedade: A inadequada recepção de Alexy pelo STF. Salvador: Juspodvm, 2016.

NEVES, Marcelo. Entre Hidra e Hércules: Princípios e regras constitucionais como diferença paradoxal do sistema jurídico. São Paulo: Martins Fontes, 2013.

OLIVEIRA, Eugênio Pacelli de. Curso de Processo Penal. 18. ed. rev. ampl. e atual. São Paulo: Atlas, 2014. 
PINHO, Ana Cláudia Bastos de. Para além do garantismo: uma proposta hermenêutica de controle da decisão penal. Belém: UFPA/Instituto de Ciências Jurídicas, 2011.

PRADO, Geraldo; MELCHIOR, Antonio Pedro. Breve análise crítica da lei n. 12.403, de 2011, que modifica o regime das cautelares pessoais no processo penal brasileiro. In. Boletim IBCCRIM - Ano 19 - No 223 - Junho 2011.

RODRIGUEZ, José Rodrigo. Como Decidem as Cortes? Para uma crítica do direito (brasileiro). Rio de Janeiro: FGV Editora, 2013.

SANGUINÉ, Odone. Prisão Cautelar, medidas alternativas e direitos fundamentais. Rio de Janeiro: Forense, 2014.

SILVA, Virgílio Afonso da. O proporcional e o razoável. Revista dos Tribunais, São Paulo, n. 798, p. 23-50, 2002.

STRECK, Lenio Luiz. Hermenêutica Jurídica e $(m)$ Crise: uma exploração hermenêutica da construção do Direito. $3^{\mathrm{a}}$ ed. Porto Alegre: Livraria do Advogado, 2001.

STRECK, Lenio. O que é isto - decido conforme minha consciência? 4.ed.rev. Porto Alegre: Livraria do Advogado Editora, 2013. 


\section{Informações adicionais e declarações dos autores (integridade científica)}

Agradecimentos (acknowledgement): Agradecemos ao Programa de Pós-graduação em Ciência Jurídica da Universidade Estadual do Norte do Paraná - UENP. Agradecimento à Capes pelo apoio e bolsa concedidos durante a pesquisa, os quais foram imprescindíveis para sua realização. Agradecimento também ao Programa de Pós-graduação em Ciência Jurídica da Universidade Estadual do Norte do Paraná (UENP).

Declaração de conflito de interesses (conflict of interest declaration): os autores confirmam que não há conflitos de interesse na realização das pesquisas expostas e na redação deste artigo.

Declaração de autoria e especificação das contribuições (declaration of authorship): todas e somente as pessoas que atendem os requisitos de autoria deste artigo estão listadas como autores; todos os coautores se responsabilizam integralmente por este trabalho em sua totalidade.

- Luiz Fernando Kazmierczak: projeto e esboço inicial (conceptualization); participação ativa nas discussões dos resultados, revisão crítica com contribuições substanciais, revisão e aprovação da versão final (reviewing and editing).

- Matheus Arcangelo Fedato: projeto e esboço inicial (conceptualization), coleta e análise de dados (data curation and investigation), levantamento bibliográfico, revisão bibliográfica, redação (writing) e participação ativa nas discussões dos resultados; revisão e aprovação da versão final (reviewing and editing).

Declaração de ineditismo e originalidade (declaration of originality): os autores asseguram que o texto aqui publicado não foi divulgado anteriormente em outro meio e que futura republicação somente se realizará com a indicação expressa da referência desta publicação original; também atestam que não há plágio de terceiros ou autoplágio. 
Dados do processo editorial

(http://www.ibraspp.com.br/revista/index.php/RBDPP/about/editorialPolicies)

- Recebido em: 30/07/2019

- Deslocamento ao V6N1: 10/08/2019

Equipe editorial envolvida

- Controle preliminar e verificação de plágio: 03/11/2019

- Avaliação 1: 11/11/2019

- Editor-chefe: 1 (VGV)

- Avaliação 2: 14/11/2019

- Avaliação 3: 01/12/2019

- Decisão editorial preliminar: 22/12/2019

- Retorno rodada de correções: 10/01/2020

- Decisão editorial final: 16/02/2020

\section{COMO CITAR ESTE ARTIGO:}

FEDATO, Matheus Arcangelo; KAZMIERCZAK, Luiz Fernando. Prisão cautelar, argumentação e proporcionalidade: uma proposta para a fundamentação das decisões judiciais. Revista Brasileira de Direito Processual Penal, Porto Alegre, vol. 6, n. 1, p. 483-514, jan./abr. 2020. https://doi.org/10.22197/rbdpp.v6i1.268

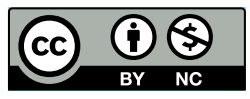

Esta obra está licenciada com uma Licença Creative Commons Atribuição-NãoComercial 4.0 Internacional. 